\title{
TEXTING AND WALKING: A CONTROLLED FIELD STUDY OF CROSSING BEHAVIOURS AND INATTENTIONAL BLINDNESS IN TAIWAN
}

\author{
C.W. PAI \\ Institute of Injury Prevention and Control, Taipei Medical University, Taiwan
}

\begin{abstract}
Recent handsets with touchscreens, as well as more advanced features including multimedia and mobile applications (apps), cause increased cognitive distraction and reduced situation awareness to a greater degree. Recently concerns have been raised about how texting, app use and listening to music affect pedestrian safety. The current research attempts to investigate the effects of phone use (talking, texting and listening to music) on the street-crossing behaviours of pedestrians. A controlled field study using video cameras was conducted. In the study, pedestrian crossing behaviours (e.g. crossing time, sudden stops, looking both ways before crossing, disobeying traffic signals) were recorded/observed. Pedestrians were classified into two groups: experimental group (talking, texting, listening to music) and control group (no phone use). Pedestrians' inattentional blindness was also examined by evaluating whether they saw an unusual object (i.e. a clown) nearby. The personal attributes and handset characteristics (e.g. unlimited Internet access, screen size and smartphone) were used as independent variables. The results indicate that the proportions of unsafe crossing behaviours (e.g. sudden stops, disobeying traffic signals, not looking both ways before crossing) were higher among distracted individuals and more pronounced among those using instant-messaging apps. These instant-message app users were the least likely to see the clown, and music listeners were the least likely to hear the horn that the clown will be honking. Contributing factors to unsafe behaviours include being a student, having a phone screen of 5 inches or larger and having unlimited third-generation Internet access.

Keywords: crossing behaviour, pedestrian safety, texting and walking.
\end{abstract}

\section{INTRODUCTION}

Considering the impact that texting may have on driving safety, recently concerns have been raised about how texting may affect pedestrian safety. Results from the studies investigating texting and walking indicate that texting creates a significantly greater interference effect on walking than does listening to music or talking on a mobile phone. Compared with pedestrians who were using their phones for other purposes (e.g. talking or listening to music), pedestrian texters were less able to maintain walking speed and more likely to pose a threat to public safety by ignoring their surroundings (or ambling across the street) [1,2]. A laboratory study by Byington and Schwebal [3] examined whether browsing the Internet on a smartphone while crossing a virtual street compromised the safety of young adult pedestrians. The study reported that distracted pedestrians were found to wait longer to cross the street, missed more safe opportunities to cross, took longer to initiate crossing when a safe gap was available, looked left and right less often, spent more time looking away from the road and were more likely to be hit or almost hit by an oncoming vehicle.

Research has suggested that texting while walking affects gait performance (i.e. ability to walk and balance), which may affect the safety of pedestrians. Rubinstein et al. [4] reported

This paper is part of the proceedings of the 22nd International Conference on Urban Transport and the Environment (Urban Transport 2016)

www.witconferences.com 
that walking and texting on a mobile phone may modify gait performance because of the increased cognitive demand placed on working memory and executive control in performing dual tasks. Lamberg and Muratori [5] recently revealed reduced walking speed and deviation from a straight path while texting messages. Recently Schabrun [6] demonstrated larger decreases in gait velocity and greater lateral deviation in young adults walking and texting compared with those walking and talking on a phone.

As Zhou et al. [7] suggested, conformity is the tendency to follow other individuals' behaviours, actions, values and ideas to avoid potential conflict with others. Literature has reported that the greater the cohesion between a group, the greater the group pressure to conform in risky behaviours [8]. In a pedestrian walking behavioural study conducted in China [7], pedestrians were found to have stronger intentions to cross against a traffic signal when surrounding pedestrians were doing so.

Research has also shown that inattentional blindness may occur in naturalistic settings caused by mobile phone conversations while driving and walking [9, 10]. Hyman et al. [10] reported that people talking on a mobile phone while walking failed to see a unicycling clown. Hyman et al. [11] later pointed out that their participants when walking and texting messages were less likely to show awareness of money in a tree (that serves as an unusual object) beside the pathway on which they were walking. These past studies have attributed inattentional blindness to the possibility that divided attention in a complex environment reduces awareness of objects that are not the focus of attention, and that the objects that people fail to see can be interesting and surprising, but are not directly related to the person's primary task.

Concurrent with other countries that have outlawed mobile phone use (including texting) while driving, Taiwan has banned mobile phone use while driving (including while riding a motorcycle). Official statistics on texting-related pedestrian casualties are few; however, with the advances in smartphone features and functions, using phones while driving may remain a frequent practice. Followed by Fort Lee in the U.S. state of New Jersey, where jaywalking pedestrians may be ticketed if caught texting and walking [12], Taiwan is developing a law to ban dangerous walking behaviour such as texting and walking [13].

The current research improves upon Byington and Schwebal [3] who examined the crossing behaviours of pedestrians distracted by mobile phone Internet browsing in a virtual environment, by conducting a field-controlled study. The main purpose of this study is to investigate the effects of phone use (talking, texting and listening to music) on pedestrian street-crossing behaviours. The present article also examines the relationship between distractions (i.e. phone use) and inattentional blindness.

\section{METHOD}

\subsection{Participants}

To be eligible, participants had to be mobile phone users (either feature phones or smartphone) and be familiar with text messaging and making phone calls. Participants were ineligible if they reported a history of medical illness relating to vision or hearing, or any conditions that restricted their ability to walk, send a text message or place a phone call. It is noteworthy here that, to identify smartphone users, smartphones can have either touchscreens or keypads. Only those using smartphones with touchscreens were included in the study as keypad smartphones were found to be very rare. In total, 1,669 participants who volunteered 
to participate in the controlled field study were recruited from Taipei Medical University, Taiwan, and the University Hospital. Volunteers were offered a small gift (i.e. a convenience store voucher worth approximately US\$2) as incentive.

\subsection{Procedures}

All participants were assigned into the experimental group or control group. The control group comprised participants who crossed the street while not distracted by listening to music, making a phone call or text messaging, and the experimental group comprised distracted individuals. Assigning an individual to the experimental group or control group was based on whether an individual was distracted. That is, an individual is assigned to the experimental group if he/she was distracted by listening to music, making a call or texting using an app or the traditional method. On the other hand, an individual is assigned to the control group if he/she was undistracted (and proceeded across the street). Participants in the experimental group can be users of smartphones or feature phones (for listening to music or talking/ texting using the traditional method). Participants in the control group can be users of either smartphones or feature phones. All participants were naïve to the purpose of the study; the only instruction they received was to cross the street. That is, the participants were instructed from the lab down to the street and crossed the street without any reason. Furthermore, participants were unaware that they were being video recorded, and were unaware of incoming text messages or phone calls that serve as distractions.

To examine the effect of listening to music, all distracted participants assigned to be music listeners were required to listen to pop music that had been loaded onto their device beforehand (the same song was used for all participants to avoid bias). Determining the effects of different music types on unsafe crossing behaviour is out of scope of the current research.

Regarding the effects of texting and making a call on crossing behaviours, the sender or receiver of the text message (or the maker of the call), and the content of the message, may be expected to influence phone use, such as whether to read or reply to the text. A pilot survey was administered to determine how the participants responded to the texts or calls from research assistants. Participants most commonly ignored the texts or calls from the strangers (i.e. research assistants), and thus texting back or calling back was rare. As a result, in the current study, each experimental group member was required to come with a friend, who was instructed to call or text message the participant before crossing the street. Immediately after the participants and their friends arrived in the lab for the study, they were isolated and further instructions were provided individually. All participants were being monitored by CCTV, which research assistants used to instruct the accompanying friend when to make the call or send the text.

Notably, if both the participant and friend had the same instant-messaging app (e.g. LINE or WhatsApp) installed on their handsets, text messages were sent and phone calls were made using the app. Traditional text message or phone call methods were used if the participants did not have the same app. The designed text message conversation topic was: 'I forgot our tutor's/supervisor's phone number. Please tell/text me the number. Thanks!' Requesting the tutor's phone number may result in various outcomes, such as participants ignoring the contact from their friend. Participants who did not ignore the contact texted the number back to their friend or called them. Participants who ignored the contact and proceeded across the street were considered undistracted walkers. 


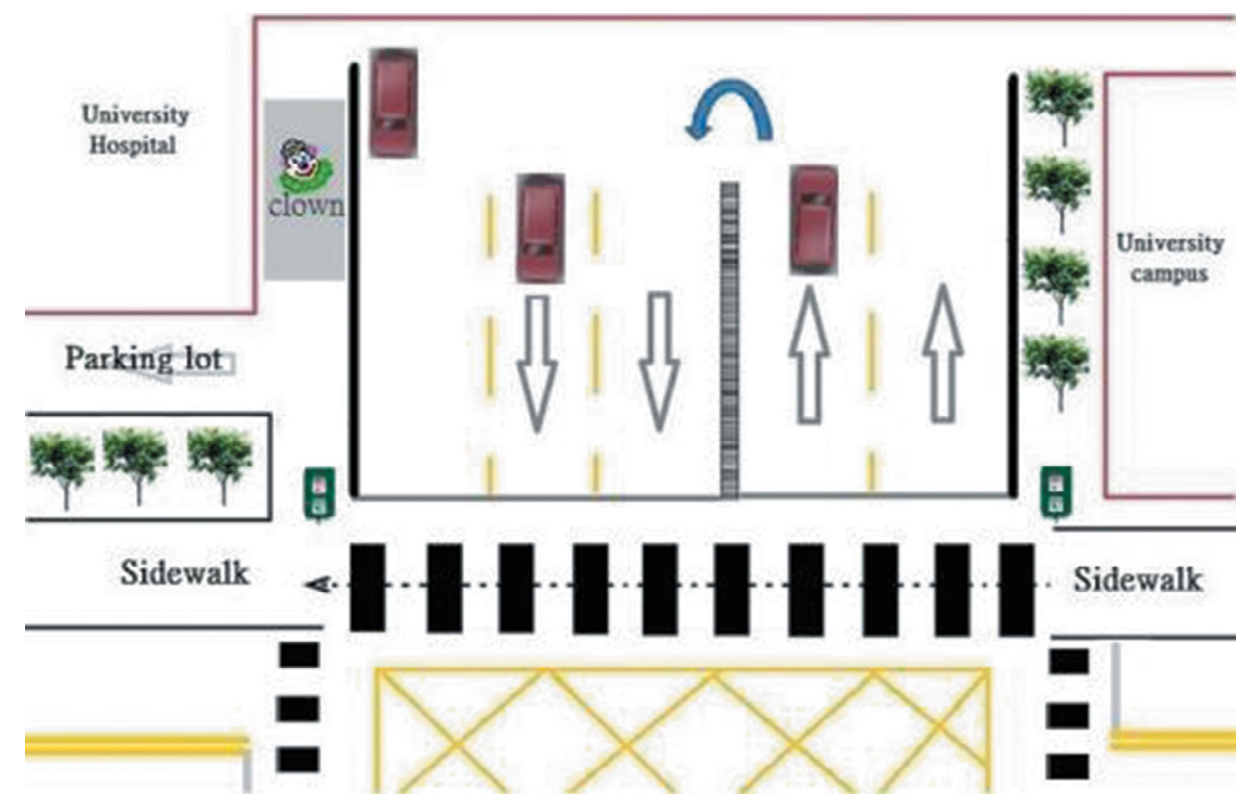

Figure 1: Designated intersection where the participants were observed.

The data were collected from May 2012 to April 2015 on weekdays during three periods of the day: morning peak hours (0700-0900), off-peak time (1200-1400) and afternoon peak hours (1600-1800). Observation during the evening was avoided because poor visibility potentially poses a greater risk of accidents to the participants (Fig. 1).

\section{RESULTS}

All participants were recruited from Taipei Medical University, Taiwan, and the University Hospital; as many as 1,702 participants volunteered to participant in the study. Although the participants were naïve to the purpose of the study, they may have been reminded by other participants (e.g. classmates or friends) who had already completed the survey. Their crossing behaviours may therefore have become more alerted, and if this occurred, the true prevalence of unsafe crossing may be higher than observed. To prevent the data from such contamination, all participants, including accompanying friends, were asked to indicate whether they were aware of the study purpose. Around $2 \%$ of the cases were identified to have known the study purpose (i.e. they will be observed, and they will receive calls/texts from their companying friends), and they were excluded from the experiment. This gives the final sample size of 1,669 participants. Of the 896 individuals in the distracted group, 450 and 446 participants were assigned to cross the street during red and green phases, respectively. Of the 773 participants in the undistracted group, 390 and 383 faced red or green phases, respectively.

Next, we investigated and analysed pedestrian crossing times and other unsafe crossing behaviours among the distracted and undistracted group (see Table 1). For those violating the red phases, their crossing tasks were aborted, and their crossing times, as well as their sudden-stop behaviour, were thus not measured. Table 1 presents the proportion of unsafe crossing behaviour by participants in each distracted group. For instance, $8.4 \%$ for texting (traditional) means that $8.4 \%$ of participants who engaged in traditional text messaging did 
Table 1: Unsafe crossing behaviours by experimental and control groups.

\begin{tabular}{|c|c|c|c|c|c|c|c|}
\hline & $\begin{array}{l}\text { Average } \\
\text { crossing } \\
\text { time }(s)^{a}\end{array}$ & $\begin{array}{l}\text { Average } \\
\text { head- } \\
\text { turning } \\
\text { frequency }\end{array}$ & $\begin{array}{l}\text { Failure to } \\
\text { look both } \\
\text { ways } \\
\text { before } \\
\text { crossing } \\
(\%)\end{array}$ & $\begin{array}{l}\text { Disobey- } \\
\text { ing the } \\
\text { signal } \\
(\%)\end{array}$ & $\begin{array}{l}\text { Sudden } \\
\text { stop }(\%)^{\mathrm{a}}\end{array}$ & $\begin{array}{l}\text { Failure } \\
\text { to see the } \\
\text { clown } \\
(\%)\end{array}$ & $\begin{array}{l}\text { Failure to } \\
\text { hear the } \\
\text { horn }(\%)\end{array}$ \\
\hline \multicolumn{8}{|l|}{$\begin{array}{l}\text { Experimen- } \\
\text { tal group }\end{array}$} \\
\hline $\begin{array}{l}\text { Texting } \\
\text { (traditional) }\end{array}$ & $18.8^{*}$ & $0.9 *$ & $8.4^{*}$ & $7.2 * *$ & 5.1 & $17.5^{*}$ & 21.6 \\
\hline $\begin{array}{l}\text { Listening to } \\
\text { music }\end{array}$ & 15.4 & $1.7^{*}$ & 3.2 & 6.6 & $0.2 *$ & 5.7 & $68.8 * *$ \\
\hline $\begin{array}{l}\text { Talking } \\
\text { (traditional) }\end{array}$ & $17.3^{*}$ & $1.3^{*}$ & 5.0 & 7.8 & 0.5 & 12.1 & 43.7 \\
\hline $\begin{array}{l}\text { Talking } \\
\text { using an app }\end{array}$ & $17.8^{*}$ & 1.1 & $7.3 * *$ & $8.1 * *$ & 0.3 & 12.6 & $45.9 *$ \\
\hline $\begin{array}{l}\text { Text } \\
\text { messaging } \\
\text { using an app }\end{array}$ & $20.5^{* *}$ & $0.7 *$ & $13.7 * *$ & $8.9 *$ & $5.7 *$ & $23.6 * *$ & 31.5 \\
\hline $\begin{array}{l}\text { Control } \\
\text { group }\end{array}$ & 15.6 & 2.3 & 1.6 & 6.7 & 0 & 3.1 & 4.7 \\
\hline
\end{tabular}

${ }^{a}$ Only those not violating traffic signals were measured $(\mathrm{N}=1,543)$.

$* p<0.05$ compared with control group.

$* * \mathrm{p}<0.01$ compared with control group.

not look both ways before crossing. The mean crossing time for the undistracted participants was $15.6 \mathrm{~s}$, and distracted participants took longer to cross the street. Among the distracted participants, those texting using an instant-messaging app took the longest to cross the street (20.5 s), and the difference was significant compared with the control group $(p<0.01)$.

Participants text messaging using an app exhibited the lowest head-turning frequency before crossing (average frequency: $0.7 ; p<0.05$ ). Those text messaging using an instantmessage app were the least likely to look both ways before crossing $(13.7 \%)$, and the difference was significant compared with the control group $(\mathrm{p}<0.01)$. Participants text messaging using an app were the most disobedient $(8.9 \% ; \mathrm{p}<0.05)$ and stopped the most while crossing $(5.7 \%$; $<$ 0.05). Pedestrian texters were the least likely to see the clown, regardless of whether they were using an app or the traditional method. Those listening to music were the least likely to hear the horn from the clown $(68.8 \% ; \mathrm{p}<0.01)$.

Table 2 reports the average crossing times, and only those who were not violating the traffic signals were measured $(\mathrm{N}=1,543)$. As reported in Table 2, participants texting using an app took significantly longer to cross the street than did undistracted participants. Participants listening to music crossed in the shortest time. Student participants took longer to cross the street than those with other occupations. Finally, participants using phones with 
Table 2: Impact of distraction events and human/phone attributes on time to cross.

\begin{tabular}{lcccr}
\hline & $\beta$ & S.E. & $95 \%$ CI & $p$-Value \\
\hline Distraction events & & & & \\
No distraction & Ref. & & & \\
Text messaging (traditional texting) & 0.37 & 0.15 & 0.21 to 0.60 & $<0.01$ \\
Listening to music & -0.20 & 0.16 & -0.39 to -0.09 & 0.41 \\
Talking (traditional) & 0.19 & 0.07 & 0.08 to 0.32 & $<0.01$ \\
Talking (using an app) & 0.26 & 0.05 & 0.13 to 0.52 & $<0.01$ \\
Texting messages (using an app) & 0.86 & 0.20 & 0.63 to 0.99 & $<0.01$ \\
Student (ref. otherwise) & 0.27 & 0.08 & 0.06 to 0.42 & $<0.01$ \\
Female & -0.12 & 0.08 & -0.27 to 0.26 & 0.33 \\
Screen size of 5 inches or larger & 0.57 & 0.12 & 0.36 to 0.83 & $<0.01$ \\
(ref. otherwise) & & & & $<0.01$ \\
Phone type & & & & \\
Smartphone & 0.63 & 0.10 & 0.43 to 0.97 & \\
Feature phone & Ref. & & & \\
3G mobile Internet & & & & \\
Unlimited Internet use & 0.83 & 0.25 & 0.65 to 0.95 & $<0.01$ \\
Restricted allowance & 0.61 & 0.16 & 0.41 to 0.77 & 0.02 \\
None & & & & \\
\hline
\end{tabular}

screens 5 inches or larger, smartphones and unlimited mobile Internet were slower than did those using phones with screens smaller than 5 inches, feature phones and restricted or no Internet data.

Several binary logit models of unsafe crossing behaviours were estimated. As reported in Tables 3 and 4, pedestrians texting using an app were the most likely to stop on the zebra crossing (odds ratio $[\mathrm{OR}]=2.98, p<0.01$ ), disobey the traffic signals $(\mathrm{OR}=2.27, \mathrm{p}<0.01$ ) and not look both ways before crossing $(\mathrm{OR}=2.59, \mathrm{p}<0.01)$ and were less likely to see the clown $(\mathrm{OR}=2.39, \mathrm{p}<0.01)$.

Among the distracted groups, listening to music was not associated with any unsafe crossing $(\mathrm{OR}=1.09$ for sudden stops, $\mathrm{OR}=1.30$ for disobeying the signals and $\mathrm{OR}=1.24$ for not looking both ways). Participants listing to music, however, were the most likely $(\mathrm{OR}=3.68)$ not to hear the horn from the clown.

Student participants were found to be more likely to perform all three types of unsafe crossing behaviours, but were less likely to exhibit the two types of inattentional blindness. Female participants were most likely than male participants to perform all unsafe crossing behaviours, though the difference was only marginally significant. However, female participants were less likely to exhibit the two types of inattentional blindness $(\mathrm{OR}=0.79$ for not noticing the clown and $\mathrm{OR}=0.86$ for not hearing the horn). 
Table 3: Odds of the three unsafe crossing behaviours by distraction activities and human or phone attributes $(\mathrm{N}=1,669)$.

\begin{tabular}{|c|c|c|c|c|c|c|}
\hline & \multicolumn{2}{|c|}{ Sudden stop } & \multicolumn{2}{|c|}{$\begin{array}{l}\text { Disobeying the } \\
\text { signals }\end{array}$} & \multicolumn{2}{|c|}{$\begin{array}{l}\text { Failure to look both } \\
\text { ways before crossing }\end{array}$} \\
\hline & OR & P-Value & OR & P-Value & OR & P-Value \\
\hline \multicolumn{7}{|l|}{ Distraction type } \\
\hline No distraction & Ref & & Ref & & Ref & \\
\hline $\begin{array}{l}\text { Texting messages } \\
\text { (traditional) }\end{array}$ & 1.76 & $<0.01$ & 1.92 & $<0.01$ & 2.13 & $<0.01$ \\
\hline Listening to music & 1.09 & 0.13 & 1.30 & 0.21 & 1.24 & 0.22 \\
\hline Talking (using an app) & 1.68 & 0.03 & 1.71 & 0.02 & 2.02 & $<0.01$ \\
\hline Talking (traditional) & 1.57 & 0.02 & 1.83 & 0.02 & 2.30 & $<0.01$ \\
\hline $\begin{array}{l}\text { Texting messages } \\
\text { (using an app) }\end{array}$ & 2.98 & $<0.01$ & 2.27 & $<0.01$ & 2.59 & $<0.01$ \\
\hline Students (ref. otherwise) & 1.60 & 0.03 & 2.31 & 0.03 & 1.56 & 0.02 \\
\hline Female (ref. male) & 1.30 & 0.13 & 1.33 & 0.16 & 0.82 & 0.16 \\
\hline $\begin{array}{l}\text { Screen size of } 5 \text { inches or } \\
\text { larger (ref. otherwise) }\end{array}$ & 1.71 & $<0.01$ & 2.11 & $<0.01$ & 2.41 & $<0.01$ \\
\hline \multicolumn{7}{|l|}{ 3G mobile Internet } \\
\hline Unlimited use & 2.65 & $<0.01$ & 1.71 & $<0.01$ & 1.89 & 0.03 \\
\hline Restricted allowance & 1.53 & $<0.01$ & 1.31 & 0.03 & 1.33 & 0.12 \\
\hline None & Ref & & Ref & & Ref & \\
\hline $\begin{array}{l}\text { Number of pedestrians } \\
\text { crossing illegally from the } \\
\text { participant side }\end{array}$ & & & 1.09 & $<0.01$ & & \\
\hline$\rho^{2}$ & & 0.39 & & 0.34 & & 0.41 \\
\hline
\end{tabular}

The probability of a participant disobeying the signal increased with the number of pedestrians crossing illegally from the same side. This result is consistent with previous studies [14] in suggesting that the decision to disobey the signals is influenced by social forces that favour herd behaviour. Pedestrians are likely to adopt herd behaviour when crossing a street; that is, they are more likely to cross if another pedestrian or pedestrians do so. This is possibly because pedestrians might feel safer making a dangerous crossing when doing so with others. The head behaviour can be particularly prevalent among people walking while using mobile phones.

Those using phones with screens 5 inches or larger exhibited an increased likelihood of engaging in the three unsafe crossing behaviours. Larger screen size was also determined to 
Table 4: Odds of the two types of inattentional blindness by distraction activities and human or phone attributes $(\mathrm{N}=1,669)$.

\begin{tabular}{|c|c|c|c|c|}
\hline & \multicolumn{2}{|c|}{$\begin{array}{l}\text { Failure to see } \\
\text { the clown }\end{array}$} & \multicolumn{2}{|c|}{$\begin{array}{l}\text { Failure to hear } \\
\text { the horn }\end{array}$} \\
\hline & OR & P-value & OR & P-value \\
\hline \multicolumn{5}{|l|}{ Distraction type } \\
\hline No distraction & Ref & & Ref & \\
\hline Text messaging (traditional) & 1.60 & $<0.01$ & 1.58 & 0.02 \\
\hline Listening to music & 1.13 & 0.39 & 3.68 & $<0.01$ \\
\hline Talking (using an app) & 1.97 & 0.17 & 2.36 & 0.03 \\
\hline Talking (traditional) & 1.57 & 0.11 & 2.13 & 0.03 \\
\hline Text messaging(using an app) & 2.39 & $<0.01$ & 2.50 & $<0.01$ \\
\hline Students (ref. otherwise) & 0.88 & 0.18 & 0.95 & 0.17 \\
\hline Female (ref. male) & 0.79 & $<0.01$ & 0.86 & 0.03 \\
\hline Screen size of 5 inches or larger (ref. otherwise) & 1.73 & 0.02 & 2.03 & $<0.01$ \\
\hline \multicolumn{5}{|l|}{$3 \mathrm{G}$ mobile Internet } \\
\hline Unlimited use & 1.76 & $<0.01$ & 2.31 & $<0.01$ \\
\hline Restricted allowance & 1.36 & 0.04 & 1.60 & 0.05 \\
\hline None & Ref & & Ref & \\
\hline$\rho^{2}$ & \multicolumn{2}{|c|}{0.31} & \multicolumn{2}{|c|}{0.35} \\
\hline
\end{tabular}

impair visual and hearing ability $(\mathrm{OR}=1.73$ for not noticing the clown; $\mathrm{OR}=2.03$ for not hearing the horn). Unlimited access to mobile Internet was associated with the three unsafe crossing behaviours; participants with unlimited Internet access were 2.65 times more likely to suddenly stop, 1.71 times more likely to disobey the signal and 1.89 times more likely not to look both ways than were participants with no mobile Internet access. These participants were also 1.76 and 2.31 times more likely not to see the clown and not hear the horn, respectively, than were participants with no mobile Internet access.

\section{DISCUSSION}

We specifically investigated the determinants of unsafe crossing behaviours in the distracted group. The results suggested that those with unlimited mobile Internet access tended not to see the clown and hear the horn. Past laboratory studies [15] have reported that distractions impair pedestrians' awareness of their surroundings. Our results further confirm that mobile phone users, in particular those with unlimited Internet access and those text messaging using an app, tended to exhibit visual and sound blindness (i.e. were less likely to see the clown or hear the horn).

The present article also contributes to the safety-research community by concluding that phone screens 5 inches or larger or unlimited Internet access are associated with the three 
unsafe crossing behaviours. Possible interventions may include educating the public about dangerous crossing behaviours that may arise from mobile phone use in general and from phones with large screens and unlimited Internet access in particular. Our result relating to large screen size may guide phone manufacturers in their decision-making process; although handsets with large screens can be more eye-catching, the divided attention caused by such screens while driving or walking should not be overlooked.

The rapid increase in the popularity of text messaging, in particular through instant-messaging app, suggests that the risk of distraction and a subsequent accident or injury will increase. Besides education, counter-measures may include engineering and environmental modifications, as well as enforcement efforts. Environmental modifications separating pedestrians from motor traffic and promoting conflict-free crossings may be effective in areas with numerous jaywalking pedestrians. The enforcement of laws against dangerous walking, including texting while walking as implemented in Fort Lee, New Jersey, may also be considered in Taiwan to reduce the risk of distractions and accidents.

Arguably, the clown may not appear within the focus of attention and may be blocked by vehicles or other pedestrians. Efforts were made to avoid these problems. First, for the clown, a 185-cm-tall student was recruited to avoid being blocked by regular-size cars (but not by larger vehicles such as buses). Second, the clown was standing right next to a parking lot where traffic may pose a conflict with crossing pedestrians, making the clown more likely to appear within the visual field of participants. We understand that the position of the clown was critical in determining whether he appeared within the visual field of the participants. However, as in well-known studies of inattentional blindness $[10,11,16]$, controlling this variable to such an extent was beyond the scope of our experimental design.

Notably, although some measures such as disobeying the signal, head-turning frequency and not looking both ways affect safety, the relevance to safety of outcome variables such as crossing speed and stopping behaviours is questionable. Although these arguments seem valid, a reduced walking speed, for instance, may leave pedestrians stranded in the street, endangering the safety of them and other road users. One may also argue that sudden stops are probably not associated with an increased accident risk; however, such behaviour may delay other pedestrians, reducing their time to finish crossing. The present article analysed pedestrian unsafe crossing behaviours but is not intended to link these behaviours to accident or injury risks. Readers are recommended to bear this in mind and that the results should be interpreted with caution.

Similar to previous observational research, the current study has strengths as well as limitations. We observed numerous individuals in a real-life environment and controlled for several influential variables, including mobile screen size and $3 \mathrm{G}$ Internet access, that have not been investigated in past studies. The current research has also controlled for whether calls and text messaging were made or transmitted using an instant-messaging app or the traditional method. The results showed that app communication was associated with the three unsafe crossing behaviours.

\section{REFERENCES}

[1] Neider, M., McCarley, J., Crowell, J., Kaczmarski, H. \& Kramer, A., Pedestrians, vehicles, and cell phones. Accident Analysis and Prevention, 42, pp. 589-594, 2010. DOI: 10.1016/j.aap.2009.10.004.

[2] Schwebel, D., Stavrinos, D., Byington, K., Davis, T., O’Neal, E. \& de Jong, D., Distraction and pedestrian safety: How talking on the phone, texting, and listening to music 
impact crossing the street. Accident Analysis and Prevention, 45, pp. 266-271, 2012. DOI: 10.1016/j.aap.2011.07.011.

[3] Byington, K. \& Schwebel, D., Effects of mobile Internet use on college student pedestrian injury risk. Accident Analysis and Prevention, 51, pp. 78-83, 2013. DOI: 10.1016/j.aap.2012.11.001.

[4] Rubinstein, J., Meyer, D. \& Evans, J., Executive control of cognitive processes in task switching. Journal of Experimental Psychology Human Perception Performance, 27, pp. 763-797, 2001. DOI: 10.1037/0096-1523.27.4.763.

[5] Lamberg, E. \& Muratori, L., Cell phones change the way we walk. Gait and Posture, 35(4), pp. 688-690, 2012. DOI: 10.1016/j.gaitpost.2011.12.005.

[6] Schabrun, M., Texting and walking: Strategies for postural control and implications for safety. PLoS ONE, 9(1), p. e84312

[7] Zhou, R., Horrey, W. \& Yu, R., The effect of conformity tendency on pedestrians' roadcrossing intentions in China: An application of the theory of planned behavior. Accident Analysis and Prevention, 41(3), pp. 491-497, 2009. DOI: 10.1016/j.aap.2009.01.007.

[8] Zimbardo, P. \& Leippe, M., The Psychology of Attitude Change and Social Influence, 3rd ed., McGraw-Hill: New York, 1991.

[9] Strayer, D., Drews, F. \& Johnston, W., Cell phone-induced failures of visual attention during simulated driving. Journal of Experimental Psychology: Applied, 9, pp. 23-32, 2003. DOI: 10.1037/1076-898X.9.1.23.

[10] Hyman, I., Matthew Boss, S., Wise, B., McKenzie, K. \& Caggiano, J., Did you see the unicycling clown: Inattentional blindness while walking and talking on a cell phone. Applied Cognitive Psychology, 24, pp. 597-607, 2010. DOI: 10.1002/acp.1638.

[11] Hyman, I., Sarb, B. \& Wise, B., Failure to see money on a tree: Inattentional blindness for objects that guided behavior. Frontiers in Psychology, 5(356), pp. 1-7, 2014. DOI: 10.1177/0018720813495280.

[12] Newcombe, A., Texting while walking banned in New Jersey town. American Broadcasting Coporation (ABC) News, 2012.

[13] Apple Daily, A fine of NTD300 is proposed, available at http://www.appledaily.com. tw/realtimenews/article/new/20140504/391453/ (accessed 19 December 2014).

[14] McGhie, A., Lewis, I. \& Hyde, M., The influence of conformity and group identity on drink walking intentions: Comparing intentions to drink walk across risky pedestrian crossing scenarios. Accident Analysis and Prevention, 45, pp. 639-645, 2012. DOI: 10.1016/j.aap.2011.09.035.

[15] Nasar, J., Hecht, P. \& Wener, R., Mobile telephones, distracted attention, and pedestrian safety. Accident Analysis and Prevention, 40, pp. 69-75, 2008. DOI: 10.1016/j. aap.2007.04.005.

[16] Simons, D., Attentional capture and inattentional blindness. Trends in Cognitive Science, 4, pp. 147-155, 2000. DOI: 10.1016/S1364-6613(00)01455-8. 